\title{
Resin Characterization and Tubular Membrane Transport with Single Gases for Ethyl Lactate Separations for Industrial Purposes
}

\author{
Edidiong Okon, Habiba Shehu, Ngozi Nwogu, Mohammed Kajama, Ifeyinwa Orakwe, \\ Edward Gobina* \\ Center for Process Integration and Membrane Technology (CPIMT), School of Engineering, The Robert Gordon \\ University, Aberdeen, UK \\ Email: e.p.okon@rgu.ac.uk, h.shehu@rgu.ac.uk, n.c.nwogu@rgu.ac.uk, m.n.kajama@rgu.ac.uk, \\ i.r.orakwe@rgu.ac.uk, ${ }^{*}$ e.gobina@rgu.ac.uk
}

Received 17 June 2015; accepted 5 September 2015; published 8 September 2015

Copyright (C) 2015 by authors and Scientific Research Publishing Inc.

This work is licensed under the Creative Commons Attribution International License (CC BY).

http://creativecommons.org/licenses/by/4.0/

(c) (i)

Open Access

\section{Abstract}

The dip-coating method has been used to prepare silica membrane. The gas flow rate relationship with the gauge pressure showed a Knudsen type of mechanism of gas transport. The flux was found to decrease with respect to temperature indicating non-activation mechanism of transport through the membrane. The order of the gas kinetic diameter with respect to the gas flow rate was $\mathrm{He}>\mathrm{Ar}>\mathrm{CO}_{2}>\mathrm{N}_{2}$ confirming a molecular sieving mechanism of gas transport. The characterisation of the resin catalysts was carried out using scanning electron microscopy (SEM). The SEM morphology of the Amberlyst 16 resin catalysts showed a defect-free surface before esterification process. Amberlyst 15 catalyst exhibited some defect on the surface indicating a lower resistance to lactic acid and decomposition at higher temperature after the esterification process at $60^{\circ} \mathrm{C}$. The order of the gas viscosity with respect to the gas flux was $\mathrm{N}_{2}>\mathrm{Ar}>\mathrm{CO}_{2}>\mathrm{He}$.

\section{Keywords}

Esterification, Resin Characterisation, Transport Mechanism, Ethyl Lactate and Permeability

\section{Introduction}

New technology has emerged in order to improve the ethyl lactate through the esterification of acid and ethanol

${ }^{*}$ Corresponding author.

How to cite this paper: Okon, E., Shehu, H., Nwogu, N., Kajama, M., Orakwe, I. and Gobina, E. (2015) Resin Characterization and Tubular Membrane Transport with Single Gases for Ethyl Lactate Separations for Industrial Purposes. Journal of Materials Science and Chemical Engineering, 3, 8-14. http://dx.doi.org/10.4236/msce.2015.39002 
using pervaporation membrane process and reactive distillation [1]. Lactic acid esterification reaction is a reversible reaction in nature; hence, the conversion of lactic acid is limited by equilibrium [2]. In order to obtain a high yield of the ester, different methods have been suggested including introducing more of the alcohol to the reaction and increasing the temperature and also employing a catalytic ceramic membrane which will help to shift the equilibrium to the product side by selective removal of water. Although the traditional method of solving equilibrium problems in esterification reactions involves the addition of an excess amount of alcohol to the reaction system, using a membrane can result in higher conversion by shifting the chemical equilibrium towards the formation of the product by in-situ removal of water from the reaction mixture [3]. Membrane-based separation technologies have been successfully employed over the years in several industrial applications including food, biotechnology, pharmaceutical and in the treatment of industrial effluents [4]. Membranes have also replaced a lot of conventional technologies because of the following advantages including: reliability, simple to operate, absence of moving parts and ability to tolerate fluctuations in flow rate and feed composition [4] [5].

Compared to other membranes, ceramic membranes have more thermal, mechanical and chemical stability. Gas transport through inorganic membranes is more complex in contrast to polymeric membranes [6]. Materials including $\mathrm{SiO}_{2}, \mathrm{Al}_{2} \mathrm{O}_{3}, \mathrm{ZrO}_{2}$ and $\mathrm{TiO}_{2}$ are the most frequently used materials for ceramic membranes. Inorganic membranes can be prepared using different methods including sol-gel, sintering, chemical deposition and dipcoating methods [7]. Generally the conventional dip-coating process involves two major steps: support dipping and support withdrawal [8]. The suitability of a ceramic membrane depends on the membrane selectivity and permeability [9]. However, gas transport through porous ceramic membrane can be explained using different mechanism of transport including surface diffusion, capillary condensation, viscous flow, molecular sieving and Knudsen diffusion [10]. Viscous flow occurs if the pore radius of the membrane is larger than the mean free path of the permeating gas molecule; in this case more collision will take place between gas molecule than with the pore walls of the membrane. Knudsen diffusion mechanism also occurs if the mean free path $(\lambda)$ of the permeating gas molecule is greater than pore diameter (d). This indicates that the Knudsen number $(K)$ is greater than 1, i.e. $K=\lambda / \mathrm{d}>1$ [11]. Molecular sieving occurs when the diameter of the gas molecule is very close to that of the pores of the membrane. In capillary condensation mechanism, separation can takes place in the pores of the membrane with mesoporous layer in the presence of condensable gas specie [6] [12]. Surface diffusion mechanism enables permeation rate relative to Knudsen diffusion in such a way that the gas is strongly adsorbed on the pore wall of the membrane [13].

\section{Experimental}

The four gases used for the carrier gas permeation tests include: nitrogen $\left(\mathrm{N}_{2}\right)$, argon $(\mathrm{Ar})$, helium (He) and carbon dioxide $\left(\mathrm{CO}_{2}\right)$. The gases were supplied by BOC, UK. The permeation test was carried out at the feed pressure drop of $0.10-1.00$ bar and at $393 \mathrm{~K}$. The membrane support was dip-coated twice before the permeation analysis. The effective length of the membrane was $36.6 \mathrm{~cm}$, while the inner and outer radius of the membrane was 7 and $10 \mathrm{~mm}$ respectively. The support modification process was carried out based on the procedure developed by Gobina (2006) [14]. Figure 1 shows the single gas permeation setup [15]. The surface morphology of the Amberlyst 15 and Amberlyst 16 resin catalysts was examined using the Zeiss EVO LS10 Scanning electron microscopy (SEM) at the magnification of $10 \mu \mathrm{m}$ and $100 \mu \mathrm{m}$ respectively.

\section{Result and Discussion}

Figure 2 shows the relationship between flow rate $\left(\mathrm{mol} \cdot \mathrm{s}^{-1}\right)$ and feed gauge pressure (bar) at $393 \mathrm{~K}$. From Figure 2, it can be seen that the gas flow increase with feed pressure at $393 \mathrm{~K}$. Gases with the higher molecular weight exhibited low flow rate indicating Knudsen flow mechanism.

Figure 3 shows the relationship between the gas flux and the inverse of viscosity of the gases. It was observed that $\mathrm{Ar}$ (17.81) and $\mathrm{N}_{2}$ (15) with the least viscosity values exhibited a higher flux in contrast to $\mathrm{CO}_{2}(22.7)$ and $\mathrm{He}$ (20) gases. Although $\mathrm{Ar}$ and $\mathrm{CO}_{2}$ gas viscosity are not close but they exhibited almost the same flux. It was suggested that there could have been some contribution of viscous flow mechanism of transport.

Figure 4 shows the relationship between the gas flow rate and the gas kinetic diameter at $393 \mathrm{~K}$ and at 0.80 bar gauge pressure. From Figure 4, it was found that the $\mathrm{He}$ and $\mathrm{CO}_{2}$ gas with the least kinetic diameter of 2.65 $\AA$ and $3.30 \AA$ respectively, showed a higher flow rate than $\mathrm{Ar}$ and $\mathrm{N}_{2}$ gas with the higher kinetic diameter of $3.40 \AA$ and $3.64 \AA$ respectively indicating molecular sieving mechanism of gas transport through the membrane. 


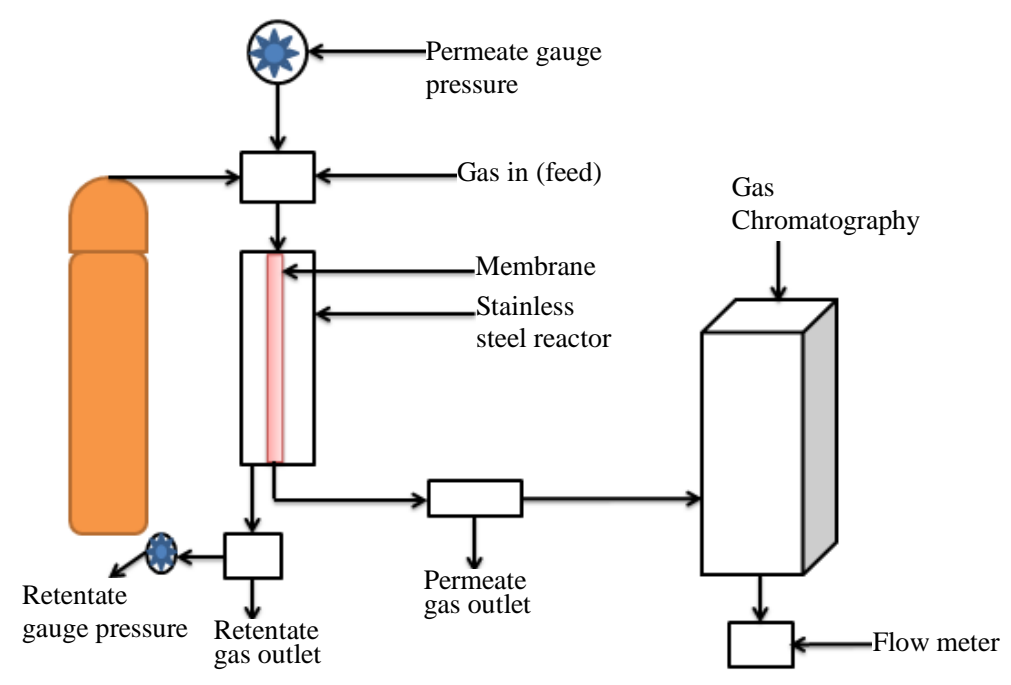

Figure 1. Single gas experimental setup [15].

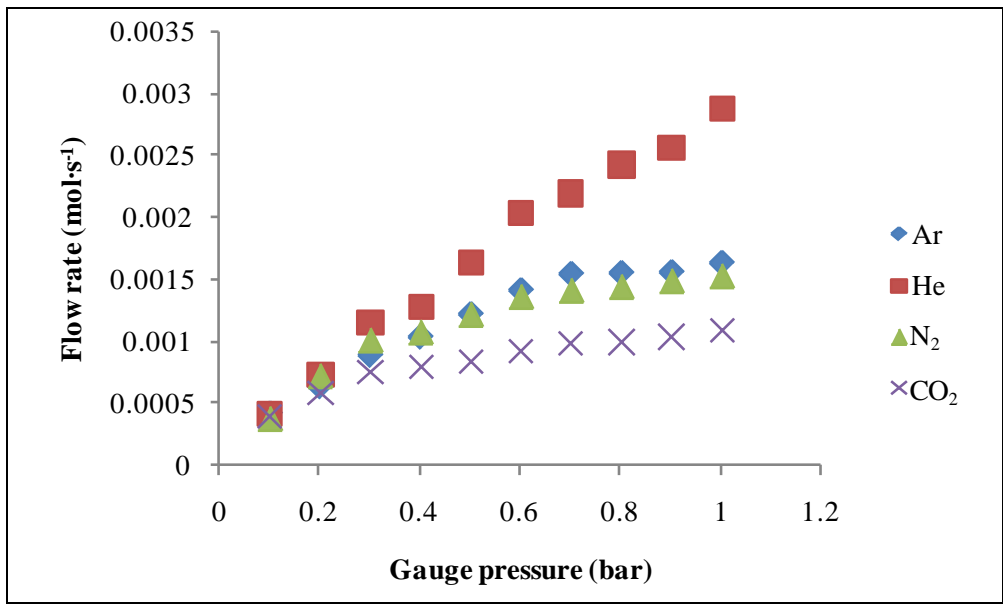

Figure 2. Flow rate $\left(\mathrm{mol} \cdot \mathrm{s}^{-1}\right)$ against gauge pressure (bar).

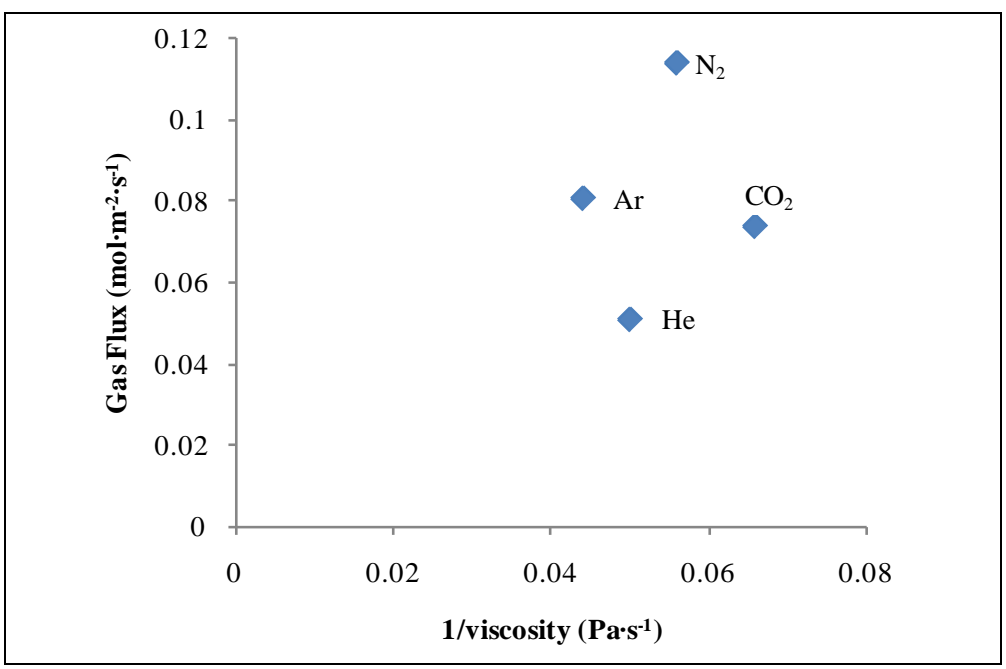

Figure 3. Gas flux $\left(\mathrm{mol} \cdot \mathrm{m}^{-2} \cdot \mathrm{s}^{-1}\right)$ against $1 /$ viscosity $\left(\mathrm{Pa} \cdot \mathrm{s}^{-1}\right)$ at 0.70 bar at 393 K. 
The permeability of the membrane was calculated to determine pore size and the mean free path of the gases through the membrane as shown in Table 1. From Table 1, the results obtained showed that the membrane pore radius for the gases was all smaller than the mean free path, indicating Knudsen mechanism of transport. This results corroborate with a report by Benito et al. [16], that Knudsen diffusion is the dominate mechanism, if the membrane pore radius is smaller than the mean free path of the molecules.

Figure 5(a) and Figure 5(b) present the SEM images of the resin catalysts before and after the esterification. The surfaces of Amberlyst 16 (Figure 5(a)) and Amberlyst 15 (Figure 5(b)) before the esterification reaction was expected to show a smooth surface. Marginal defect observed on the surface of the commercial Amberlyst 15 would probably have originated from the sulphonic acid group in which solid catalyst is made up of thereby indicating a strong catalytic effect. A similar result was obtained by Zhang et al [17]. From Figure 5(c) and Figure 5(d), it was observed that the two catalysts exhibited cracks on the surface after the esterification process although that of the Amberlyst 16 was not very pronounced. This was suggested to be the effect of temperature on the polymeric material after the esterification process. From Figure 5(d); Amberlyst 15 catalyst showed a less mechanical effect. It was also observed that this catalyst cannot withstand the applied forces of high concentrations of lactic acid from the esterification reaction. It was also observed that Amberlyst 15 exhibited less thermal stability and less resistance at $60^{\circ} \mathrm{C}$ indicating that it can decompose easily at higher temperatures. However, Amberlyst 16 was found to be more stable compared to Amberlyst 15 catalyst.

Figure 6 shows the relationship between the gas flux $\left(\mathrm{mol} \cdot \mathrm{m}^{-2} \cdot \mathrm{s}^{-1}\right)$ and temperature $\left({ }^{\circ} \mathrm{C}\right)$ at $393 \mathrm{~K}$. It can be seen from Figure 6 that the gas flux does not change significantly with temperature. It was suggested that this may be due to transport of He gas diffusing faster through the pores of the silica membrane as the temperature increases in contrast to other gases. $\mathrm{CO}_{2}, \mathrm{~N}_{2}$ and Ar gas flow decrease continuously with increase in temperature confirming Knudsen type mechanism on the silica membrane at higher gauge pressure range 0.5 bar.

Figure 7 depicts the relationship between the gas permeance and the inverse square root of the gas molecular weight at 0.60 bar and $373 \mathrm{~K}$. The experiments were performed in duplicate for repeatability. In Knudsen mechanism, the gas permeance must be directly proportional to the inverse square root of the gas molecular weight. From the result obtained in Figure 7, it was found that although $\mathrm{Ar}, \mathrm{N}_{2}$ and $\mathrm{CO}_{2}$ did fit well to the line through the origin, He was observed to deviate from the other gases. Helium transport through the silica is based on a combination of activated and Knudsen mechanisms which explains its deviation from the inverse square root law with permeance. A similar result was also obtained in our previous study [15].

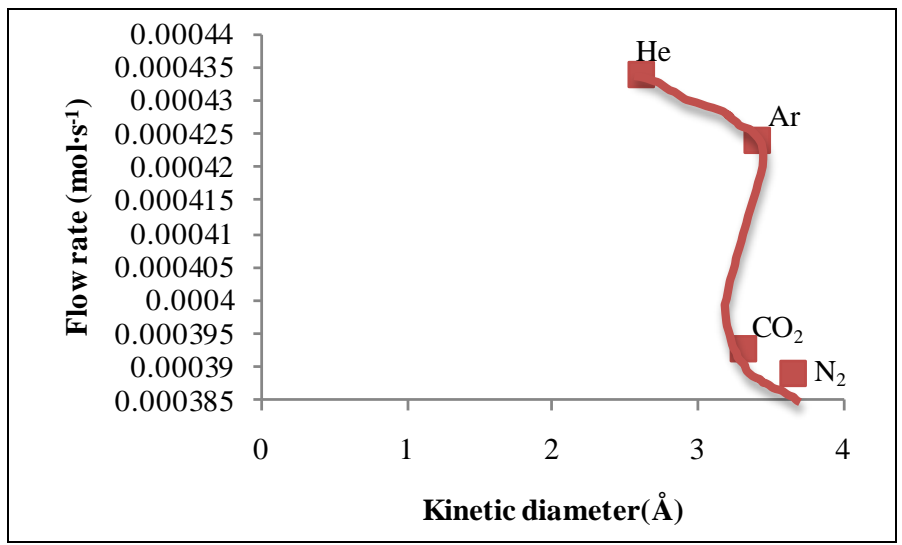

Figure 4. Flow rate $\left(\mathrm{mol} \cdot \mathrm{s}^{-1}\right)$ against kinetic diameter $(\AA)$ at 0.80 bar and $393 \mathrm{~K}$.

Table 1. Calculated values of the pore size, mean free and permeability of the four gases.

\begin{tabular}{cccc}
\hline Gas molecule & Mean free path $(\lambda) \mathbf{~ m}$ & Pore radius $(\mathbf{m})$ & Permeability $\left(\mathbf{m o l} \cdot \mathbf{m m}^{-\mathbf{2}} \cdot \mathbf{s}^{\left.\mathbf{- 1} \cdot \mathbf{P a}^{\mathbf{- 1}}\right)}\right.$ \\
\hline $\mathrm{Ar}$ & $3.15 \mathrm{E}-04$ & $4.72 \mathrm{E}-12$ & $4.258 \mathrm{E}-08$ \\
$\mathrm{He}$ & $3.63 \mathrm{E}-04$ & $1.09 \mathrm{E}-11$ & $5.253 \mathrm{E}-08$ \\
$\mathrm{~N}_{2}$ & $2.96 \mathrm{E}-04$ & $4.45 \mathrm{E}-12$ & $4.425 \mathrm{E}-08$ \\
$\mathrm{CO}_{2}$ & $1.11 \mathrm{E}-04$ & $2.22 \mathrm{E}-12$ & $1.380 \mathrm{E}-08$ \\
\hline
\end{tabular}




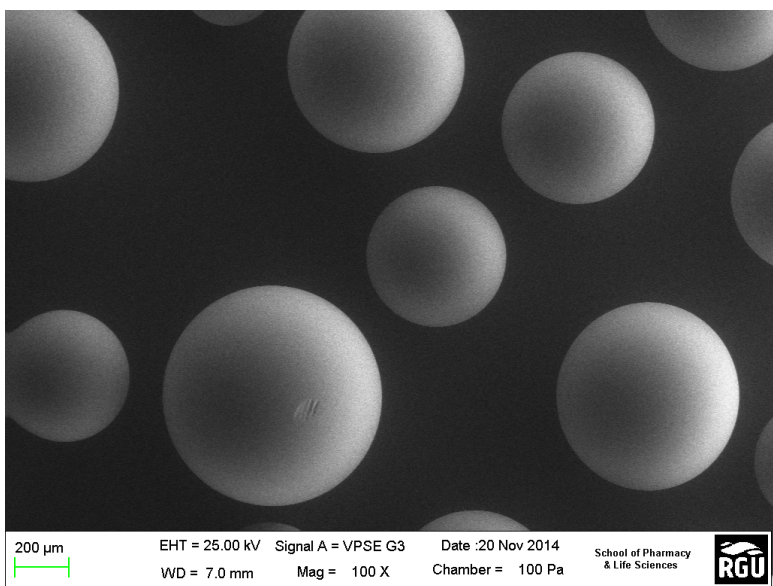

(a)

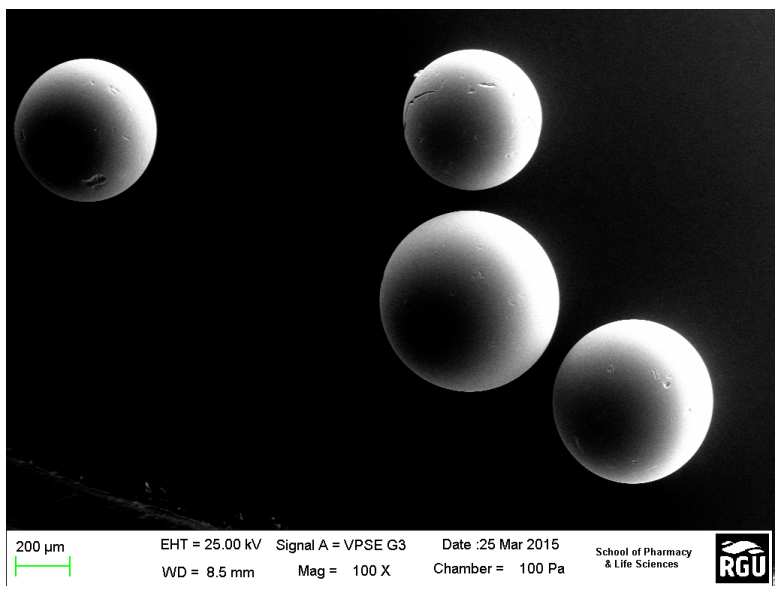

(c)

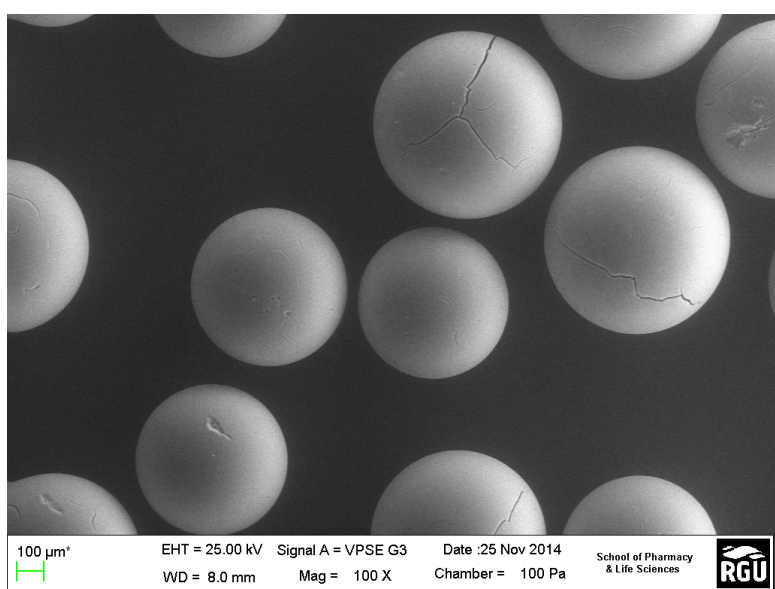

(b)

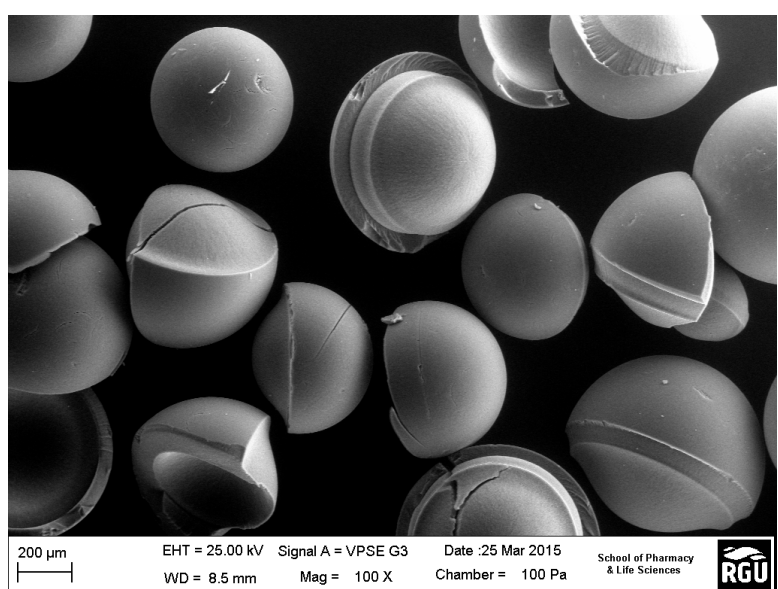

(d)

Figure 5. (a) (Amberlyst 16), (b) (Amberlyst 15), (c) (Amberlyst 14) and (d) (Amberlyst 15): SEM surface morphology of the resin catalysts before and after esterification reaction at $60^{\circ} \mathrm{C}$.

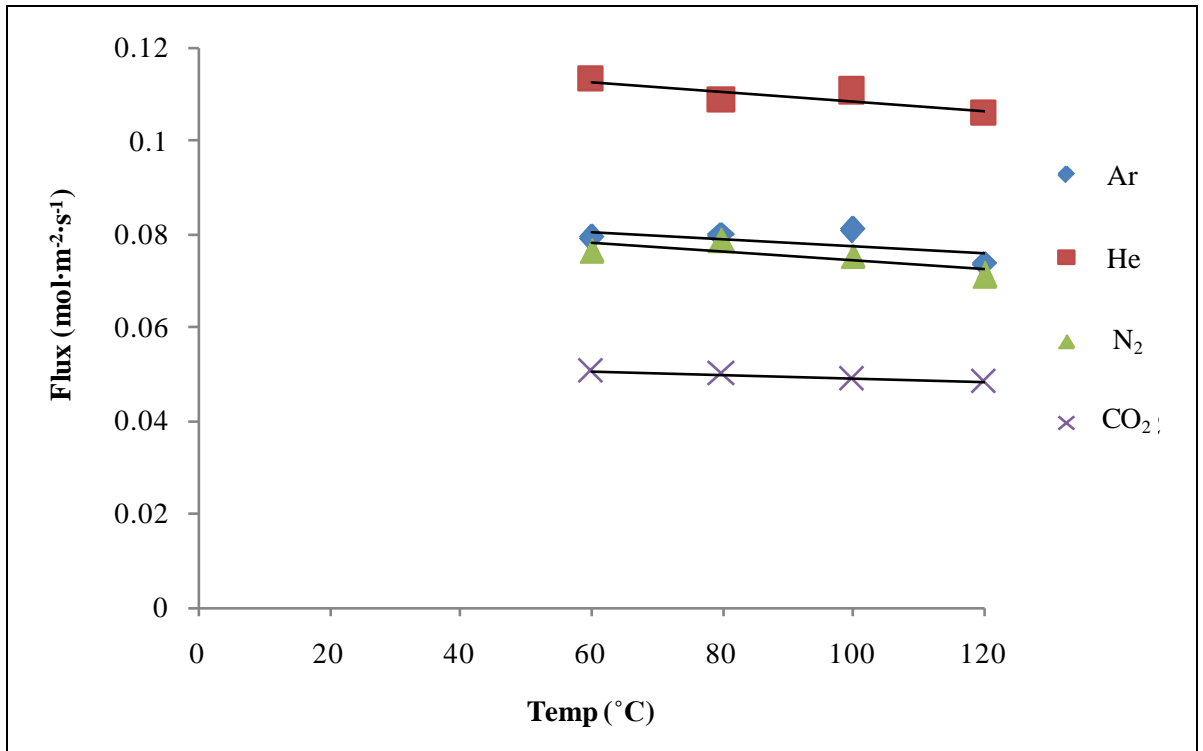

Figure 6. Flux $\left(\mathrm{mol} \cdot \mathrm{m}^{-2} \cdot \mathrm{s}^{-1}\right)$ against temperature $\left({ }^{\circ} \mathrm{C}\right)$ at 0.50 bar. 


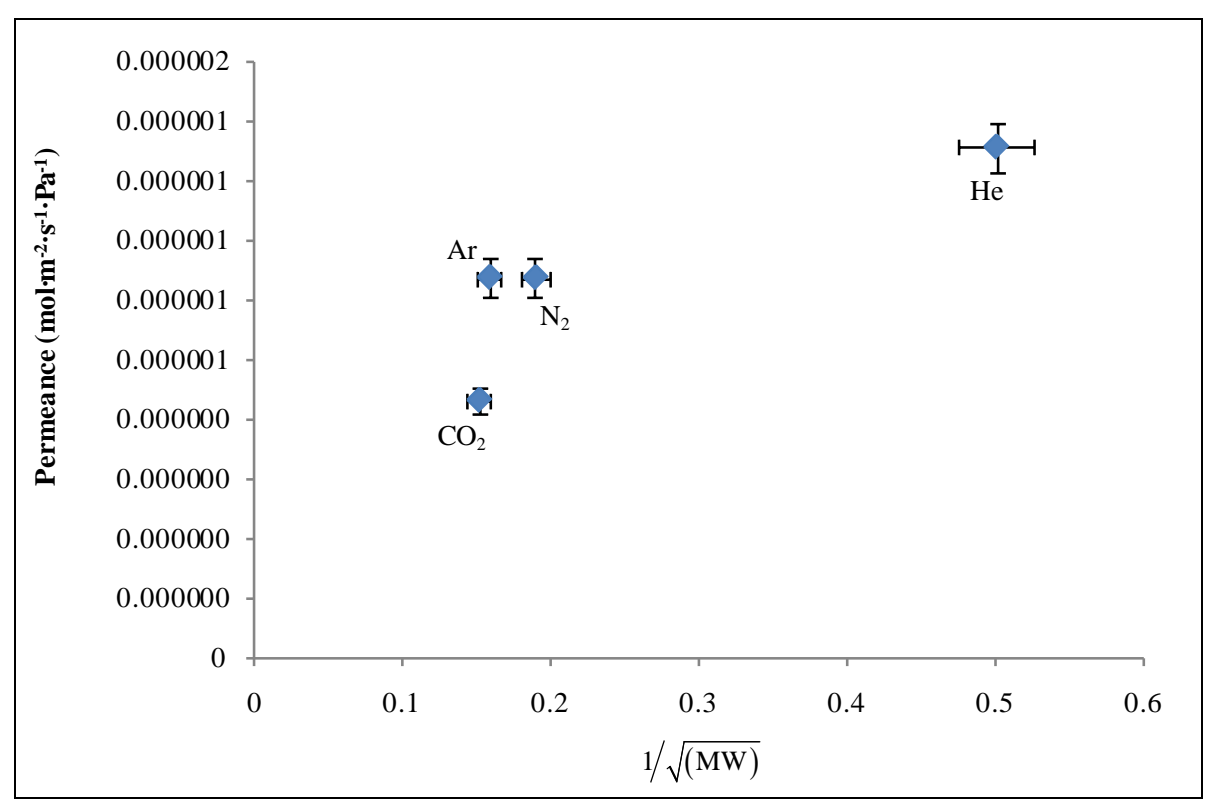

Figure 7. Permeance $\left(\mathrm{mol} \cdot \mathrm{m}^{-2} \cdot \mathrm{s}^{-1} \cdot \mathrm{Pa}^{-1}\right)$ against inverse square root of gas molecular weight at 0.60 bar and $393 \mathrm{~K}$.

\section{Conclusion}

The morphological characterisation using SEM and gas transport of tubular membrane with single gases before ethyl lactate separations has been investigated. The Amberlyst 16 reins catalysts showed defect-free surface before the esterification processes. Amberlyst 15 exhibited a serious crack on the surface after esterification processes. Amberlyst 16 catalyst was found to be more stable to heat at the esterification temperature of $60^{\circ} \mathrm{C}$ in contrast to Amberlyst 15. The membrane exhibited a molecular sieving and Knudsen type flow mechanism with some contribution of viscous flow mechanism. $\mathrm{Ar}, \mathrm{N}_{2}$ and $\mathrm{CO}_{2}$ gases showed a linear proportionality with inverse square root of molecular weight. He gas showed a deviation from the inverse square root law with permeance. The membrane pore radii for the gases were all smaller than the mean free path.

\section{Acknowledgements}

The Authors acknowledge the Centre for Process Integration and Membrane Technology (CPIMT), School of Engineering, RGU for providing the membrane and also the School of Pharmacy and life Sciences RGU for the SEM images.

\section{References}

[1] Vu, D.T., Lira, C.T., Asthana, N.S., Kolah, A.K. and Miller, D.J. (2006) Vapor-Liquid Equilibria in the Systems Ethyl Lactate Ethanol and Ethyl Lactate Water. Journal of Chemical \& Engineering Data, 51, 1220-1225. http://dx.doi.org/10.1021/je050537y

[2] Rattanaphanee, P. (2010) Factorial Design of Experiments for Comparative Study of Lactic Acid Esterification with Ethanol and n-Butanol. 2010 International Conference on Chemistry and Chemical Engineering (ICCCE), 1-5. http://dx.doi.org/10.1109/ICCCENG.2010.5560348

[3] Ameri, E., Moheb, A. and Roodpeyma, S. (2010) Vapor-Permeation-Aided Esterification of Isopropanol/Propionic Acid Using NaA and PERVAP ${ }^{\circledR} 2201$ Membranes. Chemical Engineering Journal, 162, 355-363. http://dx.doi.org/10.1016/j.cej.2010.05.018

[4] Labropoulos, A., Athanasekou, C., Kakizis, N., Sapalidis, A., Pilatos, G., Romanos, G., et al. (2014) Experimental Investigation of the Transport Mechanism of Several Gases during the CVD Post-Treatment of Nanoporous Membranes. Chemical Engineering Journal, 255, 377-393. http://dx.doi.org/10.1016/j.cej.2014.06.069

[5] Clarizia, G. (2009) Strong and Weak Points of Membrane Systems Applied to Gas Separation. Chemical Engineering Transactions, 17, 1675-1680. 
[6] Lee, H., Suda, H. and Haraya, K. (2005) Gas Permeation Properties in a Composite Mesoporous Alumina Ceramic Membrane. Korean Journal of Chemical Engineering, 22, 721-728. http://dx.doi.org/10.1007/BF02705789

[7] Mulder, M. (1996) Basic Principles of Membrane Technology. 2nd Edition, Kluwer Academic Publishers, Dordrecht. http://dx.doi.org/10.1007/978-94-009-1766-8

[8] Zhu, J., Fan, Y. and Xu, N. (2011) Modified Dip-Coating Method for Preparation of Pinhole-Free Ceramic Membranes. Journal of Membrane Science, 367, 14-20. http://dx.doi.org/10.1016/j.memsci.2010.10.024

[9] Uchytil, P., Schramm, O. and Seidel-Morgenstern, A. (2000) Influence of the Transport Direction on Gas Permeation in Two-Layer Ceramic Membranes. Journal of Membrane Science, 170, 215-224. http://dx.doi.org/10.1016/S0376-7388(99)00370-1

[10] Pandey, P. and Chauhan, R. (2001) Membranes for Gas Separation. Progress in Polymer Science, 26, 853-893. http://dx.doi.org/10.1016/S0079-6700(01)00009-0

[11] Sidhu, P.S. and Cussler, E. (2001) Diffusion and Capillary Flow in Track-Etched Membranes. Journal of Membrane Science, 182, 91-101. http://dx.doi.org/10.1016/S0376-7388(00)00546-9

[12] Javaid, A. (2005) Membranes for Solubility-Based Gas Separation Applications. Chemical Engineering Journal, 112, 219-226. http://dx.doi.org/10.1016/j.cej.2005.07.010

[13] Lee, D. and Oyama, S.T. (2002) Gas Permeation Characteristics of a Hydrogen Selective Supported Silica Membrane. Journal of Membrane Science, 210, 291-306. http://dx.doi.org/10.1016/S0376-7388(02)00389-7

[14] Gobina, E. (2006) Apparatus and Method for Separating Gases. United State Patent. Patent No.: US 7,048,778 B2. Robert Gordon University, Aberdeen, 1-12.

[15] Edidiong, O., Habiba, S., Mohammed, K., Ngozi, N., Ifeyinwa, O. and Gobina, E. (2015) Cation-Exchange Resin Characterisation and Carrier Gas Performance with Mesoporous Silica Membranes for Ethyl Lactate Separation. International Journal of Engineering Research and Technology, 4, 465-467. http://dx.doi.org/10.17577/ijertv4is040606

[16] Benito, J., Conesa, A., Rubio, F. and Rodriguez, M. (2005) Preparation and Characterization of Tubular Ceramic Membranes for Treatment of Oil Emulsions. Journal of the European Ceramic Society, 25, 1895-1903. http://dx.doi.org/10.1016/j.jeurceramsoc.2004.06.016

[17] Zhang, Y., Ma, L. and Yang, J. (2004) Kinetics of Esterification of Lactic Acid with Ethanol Catalyzed by CationExchange Resins. Reactive and Functional Polymers, 61, 101-114. http://dx.doi.org/10.1016/j.reactfunctpolym.2004.04.003 